\title{
Inferring the Potential Geographic Distribution and Reasons for the Endangered Status of the Tree Fern, Sphaeropteris lepifera, in Lingnan, China Using a Small Sample Size
}

\author{
Xueying Wei ${ }^{1,2,+}$, AJ Harris ${ }^{1,+}\left(\mathbb{D}\right.$, Yuwen Cui ${ }^{1}$, Yangwu Dai ${ }^{3}$, Hanjia Hu ${ }^{4}$, Xiaoling Yu ${ }^{1}$, Rihong Jiang 5 \\ and Faguo Wang $1,6, *$ (D)
}

Citation: Wei, X.; Harris, A.; Cui, Y.; Dai, Y.; Hu, H.; Yu, X.; Jiang, R.; Wang F. Inferring the Potential Geographic Distribution and Reasons for the Endangered Status of the Tree Fern, Sphaeropteris lepifera, in Lingnan, China Using a Small Sample Size. Horticulturae 2021, 7, 496. https:/ / doi.org/10.3390/horticulturae7110496

Academic Editors: Rosario

Paolo Mauro, Carlo Nicoletto and Leo Sabatino

Received: 20 September 2021 Accepted: 10 November 2021 Published: 15 November 2021

Publisher's Note: MDPI stays neutral with regard to jurisdictional claims in published maps and institutional affiliations.

Copyright: (c) 2021 by the authors Licensee MDPI, Basel, Switzerland. This article is an open access article distributed under the terms and conditions of the Creative Commons Attribution (CC BY) license (https:// creativecommons.org/licenses/by/ $4.0 /)$.
1 Key Laboratory of Plant Resources Conservation and Sustainable Utilization, Guangdong Provincial Key Laboratory of Applied Botany, South China Botanical Garden, Chinese Academy of Sciences, Guangzhou 510650, China; hsdweixueying@163.com (X.W.); aj.harris@inbox.com (A.H.); capebulbs@gmail.com (Y.C.); yx1272614@163.com (X.Y.)

2 College of Life Sciences, Anhui Normal University, Wuhu 241000, China

3 Nan'ao County Lantian Gardens Virescence Co., Ltd., Shantou 515900, China; daiyangwu@126.com

Houzhai Town People's Government of Nan'ao County, Shantou 515910, China; huhj2001@126.com

5 Guangxi Forestry Research Institute, Nanning 530002, China; jiangrhg@163.com

6 University of Chinese Academy of Sciences, Beijing 100049, China

* Correspondence: wangfg@scbg.ac.cn; Tel.: +86-2037093715

+ Equal contribution.

Abstract: In this study, we investigated suitable habitats for the endangered tree fern, Sphaeropteris lepifera (J. Sm. ex Hook.) R.M. Tryon, based on fieldwork, ecological niche modeling, and regression approaches. We combined these data with the characterization of spore germination and gametophytic development in the laboratory to assess the reasons why $S$. lepifera is endangered and to propose a conservation strategy that focuses on suitable sites for reintroduction and accounts for the ecology and biphasic life cycle of the species. Our methods represent an integration of process- and correlation-based approaches to understanding the distributional patterns of this species, and this combined approach, while uncommonly applied, is a more robust strategy than either approach used in isolation. Our ecological niche models indicated that cold temperature extremes, temperature stability over long- and short-terms, and the seasonality of precipitation were among the most important abiotic environmental factors affecting the distribution of S. lepifera among the variables that we measured. Moreover, distribution of this fern species is also strongly influenced by the timing of development of male and female gametes. Additionally, we observed that slope aspect, specifically south-facing slopes, facilitates more incoming sunlight for mature trees, and simultaneously, provides greater, much-needed shade for fiddleheads on account of the canopy being denser. We believe that our study can provide important guidance on the restoration of S. lepifera in the wild. Specifically, potential restoration areas can be screened for the specific environmental factors that we infer to have a critical impact on the survival of the species.

Keywords: MaxEnt; ecological niche modeling (ENM); endangered species; Cyatheaceae; environmental factors

\section{Introduction}

Since at least the beginning of the Anthropocene epoch (beginning between ca. $7000 \mathrm{BP}$ to 1964) [1], human activities have profoundly threatened the survival of other, non-human species on Earth. Human activities include overuse of resources, which are not renewable quickly enough to meet demands, fragmentation of once-continuous habitats to make way for infrastructure, and intentionally or unintentionally transporting species around the globe into new environments where they may threaten the naturally occurring 
species [2]. These activities have had the outcome of fundamentally altering the local and global patterns of geographic distributions of many organisms [3].

Understanding the natural environmental tolerances and preferences of species is fundamental to developing in-situ and ex-situ conservation strategies that seek to increase the populations of species, especially those that have become rare due to anthropogenic impacts. Unfortunately, the breadth of environmental tolerances and preferences of species cannot always be inferred by examining populations in the field. This is because it is often difficult or impossible to examine all populations or measure all environmental dimensions of a habitat and because species do not always occupy the full extent of the habitat available to them due to various biological constraints and environmental barriers $[4,5]$. To overcome these challenges, several broad classes of approaches have been utilized to extrapolate from the existing, or realized, distributions, of species to infer their potential distributions [6]. Among these classes are process-based approaches and correlative approaches. Process-based approaches focus on aspects of species biology, such as dispersal capabilities and pollination syndrome (i.e., in the case of plants). In contrast, correlative approaches involve building models based on existing distributional sites and environmental factors at those sites to make inferences about the potential distribution. At present, one of the most common correlative approaches is ecological niche modeling (ENM), especially via maximum entropy in MaxEnt [7]. Process-based and correlative approaches have exceptional potential in combination [8] to inform conservation strategies because the former can predict the natural potential of a species, while the latter can elucidate in what environments and geographic locations human-mediated conservation efforts may protect and encourage that potential. However, unfortunately, process-based and correlative approaches are rarely used together.

In this study, we sought to combine process-based understanding with correlative modeling to infer the potential distribution of Sphaeropteris lepifera (J. Sm. ex Hook.) R.M. Tryon, a tree fern that mainly occurs in China [9]. S. lepifera is a large species, characterized by an erect trunk (often more than $6 \mathrm{~m}$ tall and up to $20 \mathrm{~cm}$ in diameter near base) bearing distinct leaf scars [10]. Its leaves are pale green to green, about $3 \mathrm{~m}$ long, with scales and spreading hairs on the abaxial sides. The sori are often on the back of the smallest leaf divisions, or pinnules, and lack indusia. S. lepifera differs from S. guangxiensis Y.F. Gu \& Y.H. Yan by having sparse spiny warts on its laminae and pinnae rachides and small scales on the pinnae rachides and abaxially on pinnule rachides. S. guangxiensis lacks the scales and warts on these structures [11]. This tree fern is listed as endangered within China as a grade two protected plant [12]. S. lepifera is treated in the family Cyatheaceae and is valued medicinally [13], horticulturally [14], and as a scientific model for evolution and biogeography $[15,16]$. Despite its present conservation status, this fern represents an ancient lineage that originated ca. 200 million years ago, became relatively widespread, and, later, underwent extinctions leading to its present restricted distributional range [17]. Thus, it has survived and multiplied since the Mesozoic time period. Within China, S. lepifera is primarily distributed in Taiwan [10], but a few wild populations have been found in coastal areas of mainland China, such as in Guangxi and Yunnan, including on near-shore islands, like Hainan [18-20]. Moreover, the species has also been discovered in Japan (Ryukyu Islands) and the Philippines, where it is likely to be native [21-24]. In Guangdong Province of China, S. lepifera was first found on Nan'ao Island of Shantou City by the Second National Key Protected Wild Plant Resources Survey of Guangdong Province in 2018. At present, the Nan'ao Island population, while tiny, is the only population in Guangdong Province showing new plant recruitment. Thus, the population is presently protected in-situ [25].

The causes of a rarity of S. lepifera have been considered in several prior studies [26-28]. One set of possible causes are environmental constraints on reproduction; especially on the ability of flagellated, swimming sperm to reach the female reproductive apparatus, the archegonium. In S. lepifera, the sperm originates from antheridia, which separated in space on the gamete-producing body from archegonia, thus necessitating at least a thin film of water for fertilization to occur. Aside from water, other constraints on sperm reaching 
archegonia may especially arise due to the presence of heavy metal pollutants in the environment. For example, the rotation frequency and displacement speed of the flagella of sperm are negatively impacted by lead $\left(\mathrm{Pb}^{2+}\right)$, while cadmium $\left(\mathrm{Cd}^{2+}\right)$ may inhibit the ability of sperm to follow chemical signals that otherwise guide them to receptive archegonia [26,27]. However, heavy metals are likely not the main reason for limitations in reproduction asany species of Cyatheaceae have been shown to produce gametophytes but not sporophytes under experimental conditions where soil nutrients are free of heavy metals [28]. There are 19 species of Cyatheaceae in China with a protected conservation status [29], and only nine species, including S. lepifera, have been successfully bred under controlled conditions [28,30].

Protection of a species requires not only a detailed understanding of its unique biology but also accurate models of its environmental tolerances to support both meaningful in-situ and ex situ conservation actions. Recent developments in ENM have led to its application in diverse conservation issues, including prediction of suitable habitat and species ranges [31,32] and how human activities affect the distribution of species [33,34], but applications for the conservation of protected species are still somewhat limited, especially in combination with the biology of the species.

The main objective of our study of S. lepifera was to apply process-based understaning with correlative-based modeling to species distributional modeling to (1) determine the main environmental and biological factors affecting the wild distribution of the species, so as to better focus the scope of conservation and (2) assess suitable areas for ex situ conservation. We especially sought to find suitable areas in Guangdong, Hong Kong, and Guanxi Provinces for ex situ conservation because these places had or have wild populations of S. lepifera. To accomplish our study, we focused on the population on Nan'ao Island, which is the only one within the province that has been observed to undergo natural recruitment without human intervention. By comprehensively analyzing the environment of S. lepifera on Nan'ao Island and its environmental interactions, we expect to determine other similarly suitable areas for the species for reintroduction. We believe that our results provide a comprehensive framework for future endeavors at protection, reintroduction, and sustainable utilization of $S$. lepifera.

\section{Study Area and Methods}

\subsection{Field Investigation}

From 2018 to 2020, we carried out field surveys on Nan'ao Island of Guangdong Province. The island is located at $116^{\circ} 53^{\prime}-117^{\circ} 19^{\prime} \mathrm{E}$ and $23^{\circ} 11^{\prime}-23^{\circ} 32^{\prime} \mathrm{N}$ within the subtropical maritime climate zone, having four seasons, including mild winters and relatively cool summers. Within Nan'ao Island, S. lepifera occurs on the main island, which has an area of $111.44 \mathrm{~km}^{2}$.

On Nan'ao Island, we investigated plant recruitment of populations of S. lepifera as well as diameter, height, crown breadth, and health status of adult individuals of the species. We regarded adults as those individuals with heights greater than $3 \mathrm{~m}$.

To determine the vascular plant composition of the community where S. lepifera is located, we also performed a Drude scale analysis, which is a quantitative method of assessing taxonomic composition, abundance, and cover [35,36]. To accomplish this, we established $20 \mathrm{~m} \times 20 \mathrm{~m}$ plots centered around adult individuals and surveyed all cooccurring vascular plants within four $10 \times 10 \mathrm{~m}$ quadrats nested within each plot. Within each quadrat, we sought to assign each species to one of the seven levels of the Drude scale [37]: plants of high sociability (soc; plantae sociales), three levels of copious or numerous (cop1-3; copiose intermixtae), sparse-sporadic (sp; sparsae, sporadice intermixtae), solitary (sol; plantae solitariae), and low abundance and/or singular individuals (uni; unicum). Assignments to these groups were determined based on relative-cover (relative cover $=$ species cover/quadrat area), and the specific classification was as follows: soc ( $r c \geq 75 \%$ ); cop3 $(75 \%<r c \leq 50 \%)$; $\operatorname{cop} 2(50 \%<r c \leq 25 \%)$; $\operatorname{cop} 1(15 \%<r c \leq 25 \%)$; sp $(5 \%<r c \leq 15 \%)$; sol $(5 \%<r c \leq 3 \%)$; uni $(r c \leq 2 \%)$, where $r c$ refers to relative cover. We performed the Drude 
analysis separately for the tree, shrub, and herb layers, which we delimited on the basis of height with shrubs being 3-6 $\mathrm{m}$ tall and trees and herbs being greater and lesser in height, respectively.

\subsection{Reintroduction Experiments}

From July to September 2020, we carried out reintroductions of S. lepifera to Nan'ao Island using plants initially grown in the greenhouse. We planted a total of 120 fiddleheads that had been growing in the greenhouse for about six months; 40 at the site of the existing population located in Nan'ao Island, and 80 others divided into two sites selected for translocation experiments. We also conducted preliminary translocation experiments at Maofeng Mountain in Guangzhou, Renhua County in Shaoguan, and Bajia Town in Yangchun, based on preliminary site assessments. At these sites, we planted 20 plants each, and at all sites, including Nan'ao Island, we planted the fiddleheads near a shady slope with a stream. We performed surveys at all sites of reintroduction and translocation in February 2021 to determine fiddlehead survival.

\subsection{Gametophytic Development}

In order to investigate possible biological reasons for the relative rarity of S. lepifera, we conducted a spore breeding experiment. Ferns have a relatively unique life cycle in which both gametophytes and sporophytes can live independently. However, compared with the sporophyte, the structure of the gametophyte of S. lepifera is small, fragile, and composed of only one cell layer, whereas the sporophyte is ultimately arborescent. Therefore, gametophytic development of S. lepifera might be involved in its rarity or its distributional patterns.

We studied gametophytic development using spores newly germinated under lab conditions. We obtained the spores in September 2018 at our field site on Nan'ao Island. Specifically, we collected 50 mature sporophylls from two individuals of S. lepifera and stored these in paper bags in a cool and ventilated place until the spores fell off naturally after about seven days. We separated the spores from the dry vegetative material and stored them at $4{ }^{\circ} \mathrm{C}$ before further processing.

For germination, we placed the spores on $1 / 2$ concentration MS medium after disinfecting them by applying $4 \% \mathrm{NaClO}$ solution for $5 \mathrm{~min}$. We grew the spores in culture under $16 \mathrm{~h} / \mathrm{d}$ of 5000 Lux at $25^{\circ} \mathrm{C}$ following recommendations for this species in a prior study [38]. Beginning on the third day, we sampled spores for microscopic examination every other day of two weeks. We selected characteristic spores for making into temporary slides at different stages, which we photographed under an OlympusBX43 light microscope.

Following the observations of germination, we transplanted the four-week-old gametophytes to sterilized soil. We divided this cohort of plants into four treatment groups containing 90-100 gametophytes each to determine tolerances of the species to temperature and moisture conditions. For temperature, we grew one group at $18{ }^{\circ} \mathrm{C}$ and the other at $25^{\circ} \mathrm{C}$ both with daily watering. For moisture, we watered one group daily and the other once per week, and grew these plants at $25^{\circ} \mathrm{C}$. We regarded $25^{\circ} \mathrm{C}$ and daily watering as "normal" (or control) growth conditions based on field surveys and the available literature. In all other respects, factors between the groups, such as lighting, were maintained as constant. One month later, we counted the number of sporophytes as a measure of successful fertilization.

\subsection{Ecological Niche Modeling}

We generated ENMs in MaxEnt 3.4.1 to predict potentially suitable distributional areas for S. lepifera. For generating ENMs in MaxEnt, we obtained occurrence data from three sources: our field site where a natural population occurs, populations conserved ex situ in natural reserves, and georeferenced specimen records [9] from the Global Biodiversity Information Facility (GBIF) [9]. Using all obtained data records, we performed data thinning with resampling to only one occurrence per $1 \mathrm{~km} \times 1 \mathrm{~km}$ area using the $\mathrm{R}$ 
package, dismo [39] in R 4.0.5 [40,41]. Following data thinning, 409 occurrences remained, including one point from our field site and five ex-situ conservation sites in Guangdong Province (Table 1, Table S1).

Table 1. Specimen data from our field site and ex situ reintroduction areas.

\begin{tabular}{ccccc}
\hline Source & Province & City & Longitude & Latitude \\
\hline field site & Guangdong & Shantou & 117.072 & 23.444 \\
ex situ & Guangdong & Shaoguan & 113.751 & 25.076 \\
ex situ & Guangdong & Yangjiang & 111.520 & 21.963 \\
ex situ & Guangdong & Shantou & 117.072 & 23.444 \\
ex situ & Guangdong & Guangzhou & 113.444 & 23.283 \\
ex situ & Guangdong & Shantou & 117.071 & 23.442 \\
\hline
\end{tabular}

We constructed the ENMs using the 19 environmental BioClim variables from WorldCLIM 2.0 (Bio1-Bio19) [42-44], as well as slope and aspect derived from the Digital Elevation Model (DEM) downloaded from the same source. We also obtained landcover data as a raster map from the literature [45], and human population data from the Center for International Earth Science Information Network (CIESIN) [46]. We did not directly include elevation, which is widely known to be tightly linked with temperature variables. We obtained or resampled all variables at 30 arc-second resolution and clipped them to the boundaries of the distributional map that we established using the Database of Global Administrative Areas (GADM) [45].

Within MaxEnt, we determined the contribution of each environmental variable to the model as a whole by performing a jackknife test as an extension of model building. At the same time, in order to test the robustness of the model, we repeated the modeling process 12 times through the crossvalidate method [47], and we used "random seed" to randomize each run. We applied the area under the curve (AUC) to determine the predictive ability of each model.

\section{Results}

\subsection{Germination and Fertilization Observations and Experiments}

S. lepifera exhibits a typical fern life cycle with generational alternation between the gametophyte and sporophyte stages. We observed that the sporangia of S. lepifera produce single-celled meiotic spores in April and October each year (Figure 1). The spores germinate in about 60-70 days via the vittaria-type germination pattern. The center of each spore (Figure 1A) contains oil droplets, and germination starts with the exertion of a rhizoid (Figure 1B-E). The apical chloroplast-bearing cells opposite the rhizoid development (Figure 1E) become enlarged, and the emerging prothallus (Figure 1F) develops several rhizoids on its ventral surface. The structure of the gametophyte is simple but with differentiation of the dorsal and ventral surfaces. In particular, when the gametophyte matures, there are many antheridia (Figure $1 \mathrm{G}$ ) and archegonia (Figure $1 \mathrm{H}$ ) on the ventral surface. Antheridia generate sperm that must swim in the water and sense the chemical attractants secreted by the archegonia to complete the fertilization.

Warm temperatures and high moisture appear essential for fertilization to occur in S. lepifera. Specifically, we found that fertilization (evidenced by production of a sporophyte) had visually-assessed higher success rate among plants grown at $25^{\circ} \mathrm{C}$ than $18{ }^{\circ} \mathrm{C}$. Moreover, we found that watering every day had an important impact on the formation of sporophytes, possibly related to maintaining high humidity (Figure 1I). In fact, we found that gametophytes that were watered only once weekly became malformed and yielded unproductive sporophytes. 

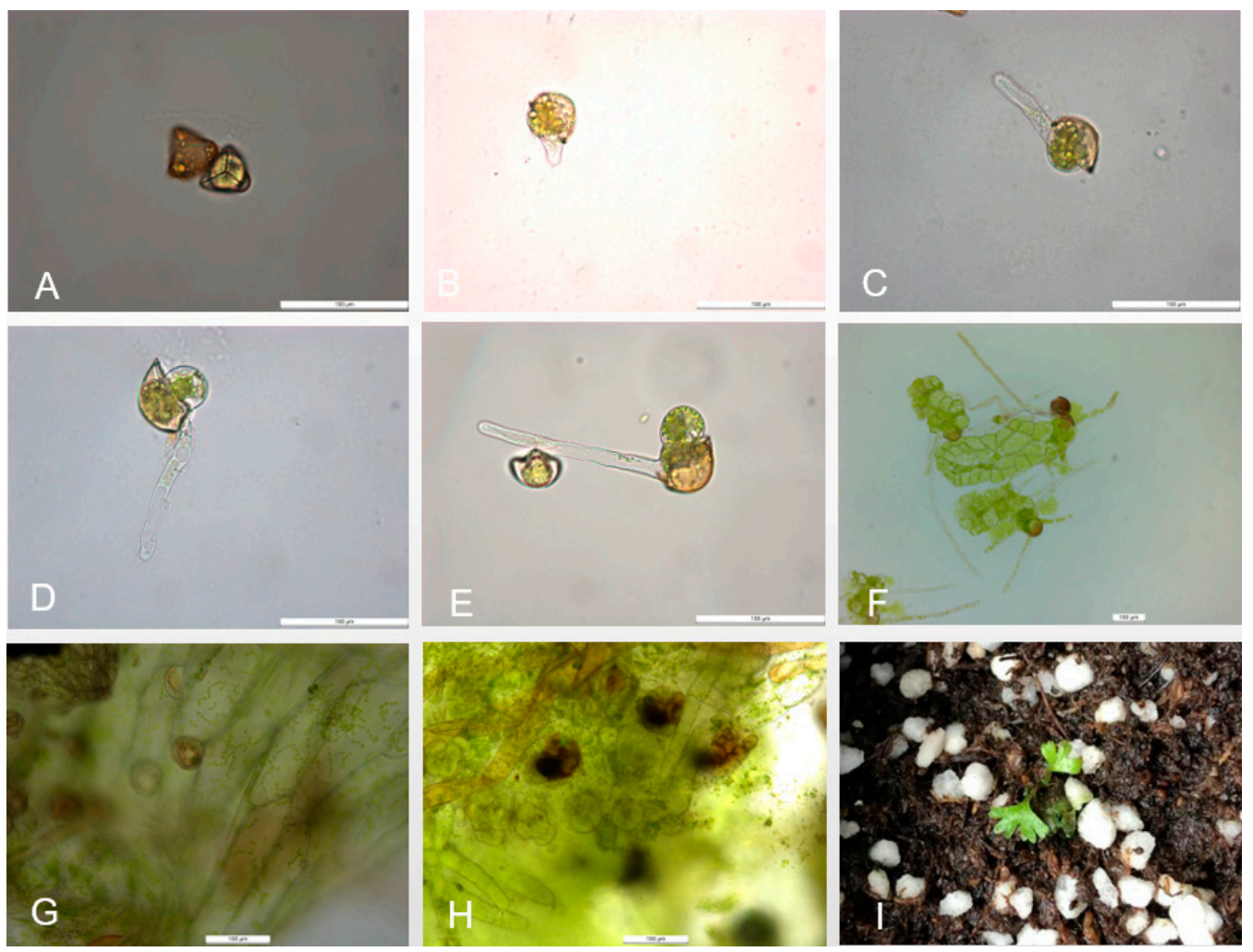

Figure 1. Spore germination process of Sphaeropteris lepifera. (A) Spore of S. lepifera (center of each spore contains oil droplets). Scale bar $=50 \mu \mathrm{m}$. (B-E) Spore germination. Scale bar $=100 \mu \mathrm{m}$. (F) Prothallus. Scale bar $=100 \mu \mathrm{m}$. (G) Antheridium. Scale bar $=100 \mu \mathrm{m}$. (H) Archegonium. Scale bar $=100 \mu \mathrm{m}$. (I) Young sporophyte. Scale bar $=10 \mathrm{~cm}$.

\subsection{Ecological Niche Modeling and Importance of Environmental Variables}

Our ENM result for S. lepifera showed that the most suitable habitat was found on northern Taiwan, along the central and western coast of Guangdong, on coastal Guangxi and Yunnan, and on near shore islands south of these provinces, such as Nan'ao. Areas of moderate suitability included coastal mountains. The AUC was 0.983 (Table 2, Figure 2A) suggesting that our model was robust. Notably, among reintroduction sites, only Shaoguan was predicted as environmentally unsuitable.

Our estimates of the relative contributions of the sampled environmental variables to the MaxEnt model showed that mean diurnal range (Bio02) contributed the most to the model $(29.3 \%$ ) followed by temperature seasonality (Bio04, 24.7\%), precipitation of the coldest quarter (Bio19, 13.5\%), and mean annual precipitation (Bio12, 11.7\%) (Table 2). Precipitation of the coldest quarter was also the most important variable based on permutation $(66.6 \%)$.

The jackknife test of variable importance (Figure 2B-D) showed that, overall, models showed roughly equal gains when any one variable was excluded. However, the highest training and test gain (Figure 2B,C) for a variable used in isolation were for mean diurnal range (Bio02), followed by temperature seasonality (Bio04), mean temperature of the coldest quarter (Bio11), isothermality (Bio03) and precipitation of the warmest quarter (Bio18). The first two of these are in agreement with the measured percentage contributions, the mean temperature of the coldest quarter is consistent with the permutation result, and the others are broadly congruent with the inference that temperature and precipitation variability are critical for the species. The AUC calculations under the jackknife test (Figure 2D) showed a similar pattern as the training and test gain, except that the mean annual temperature (Bio01) also showed notable predictive capability in isolation. 
Table 2. Contributions of the environmental variables to the MAXENT models using the 19 bioclimatic variables as well as slope, aspect, land cover, and population.

\begin{tabular}{|c|c|c|c|}
\hline Code & Environmental Factor & Percent Contribution & $\begin{array}{l}\text { Permutation } \\
\text { Importance }\end{array}$ \\
\hline Bio01 & Annual Mean Temperature & 0.4 & 0 \\
\hline Bio02 & $\begin{array}{l}\text { Mean Diurnal Range (Mean of monthly (max } \\
\text { temp-min temp)) }\end{array}$ & 29.3 & 4.9 \\
\hline Bio03 & Isothermality $(\mathrm{Bio} 2 / \mathrm{Bio})(\times 100)$ & 3.7 & 7.4 \\
\hline Bio04 & Temperature Seasonality (standard deviation $\times 100$ ) & 24.7 & 0.6 \\
\hline Bio05 & Max Temperature of Warmest Month & 1 & 1.2 \\
\hline Bio06 & Min Temperature of Coldest Month & 0.1 & 0.1 \\
\hline Bio07 & Temperature Annual Range (Bio5-Bio6) & 4.1 & 0.4 \\
\hline Bio08 & Mean Temperature of Wettest Quarter & 0.6 & 1.1 \\
\hline Bio09 & Mean Temperature of Driest Quarter & 0.1 & 0 \\
\hline Bio10 & Mean Temperature of Warmest Quarter & 0.5 & 0.2 \\
\hline Bio11 & Mean Temperature of Coldest Quarter & 2.1 & 5.7 \\
\hline Bio12 & Annual Precipitation & 11.7 & 3.7 \\
\hline Bio13 & Precipitation of Wettest Month & 0.1 & 0.3 \\
\hline Bio14 & Precipitation of Driest Month & 0.9 & 0.8 \\
\hline Bio15 & Precipitation Seasonality (Coefficient of Variation) & 0.2 & 0.5 \\
\hline Bio16 & Precipitation of Wettest Quarter & 0 & 0 \\
\hline Bio17 & Precipitation of Driest Quarter & 0.3 & 0.3 \\
\hline Bio18 & Precipitation of Warmest Quarter & 4.7 & 3.7 \\
\hline Bio19 & Precipitation of Coldest Quarter & 13.5 & 66.6 \\
\hline Slope & Slope & 0.3 & 0.1 \\
\hline Aspect & Aspect & 0.3 & 0.3 \\
\hline Landcover & Landcover & 0.1 & 0.1 \\
\hline $\begin{array}{l}\text { Human } \\
\text { population }\end{array}$ & Human population & 1.4 & 1.9 \\
\hline
\end{tabular}

\subsection{Community Composition}

We observed that the forests of Nan'ao Island mainly comprised mixed stands of Acacia confusa Merr. and Pinus massoniana D. Don with wild shrubs from the families Rosaceae, Rutaceae, and Theaceae. According to the Drude abundance analysis of the community composition of S. lepifera (Table 3), the tree layer is mainly composed of Machilus chinensis (Benth.) Hemsl., Schefflera heptaphylla (L.) Frodin, Cunninghamia lanceolata (Lamb.) Hook. and Acacia confusa and is about 8-13 m in height. The shrub layer is dominated by Psychotria rubra (Lour.) Poir. and is about $1.2-1.5 \mathrm{~m}$ in height. The herb layer consists of Eleutherococcus trifoliatus (L.) S.Y. Hu, Blechnum orientale L., Boehmeria nivea (L.) Gaudich., Cyclosorus parasiticus (L.) Farw., Deparia lancea (Thunb.) Fraser-Jenk., Dryopteris fuscipes C. Chr., Pteris fauriei Hieron., Alocasia odora (Roxb.) K. Koch, Adiantum flabellulatum L., Lygodium japonicum (Thunb.) Sw., Mussaenda pubescens W.T. Aiton, and Liriope spicata (Thunb.) Lour.

\subsection{Preliminary Reintroduction Experiment}

The survey in February 2021 revealed that 14 of 40 introduced individuals of S. lepifera survived at the site of the original population on Nan'ao Island compared with 27 of 40 and three of 40 at the two nearby sites. In addition, Maofeng Mountain in Guangzhou, Renhua County in Shaoguan, and Bajia Town in Yangchun five, 10, and five survived, respectively, of the 20 planted. The environmental conditions of the site are shown in Table 4. 


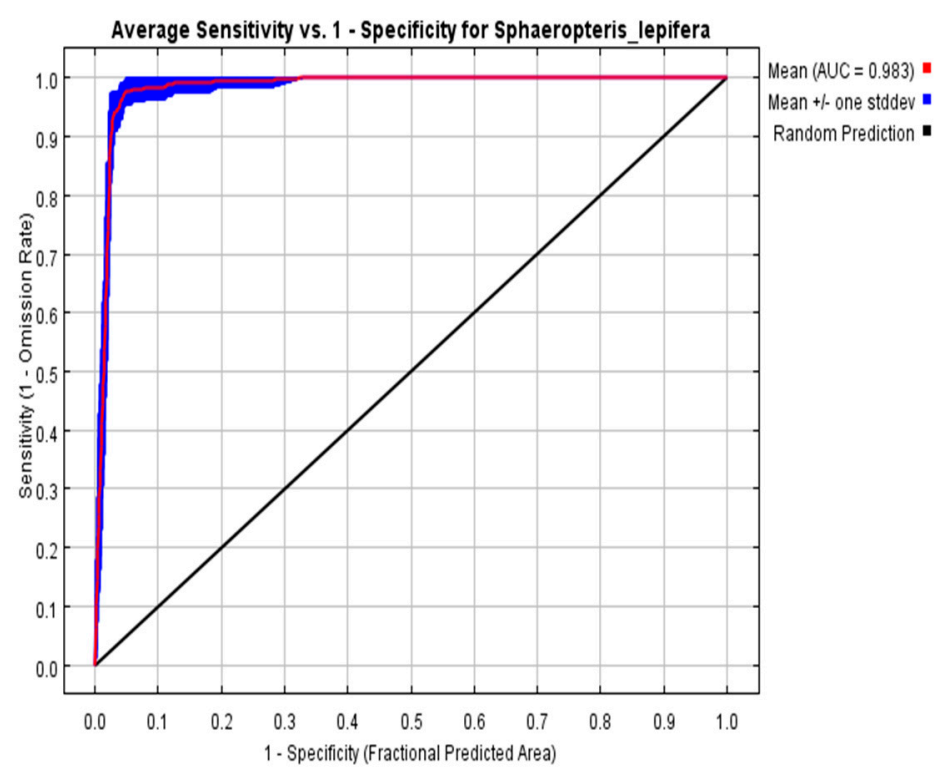

(A)

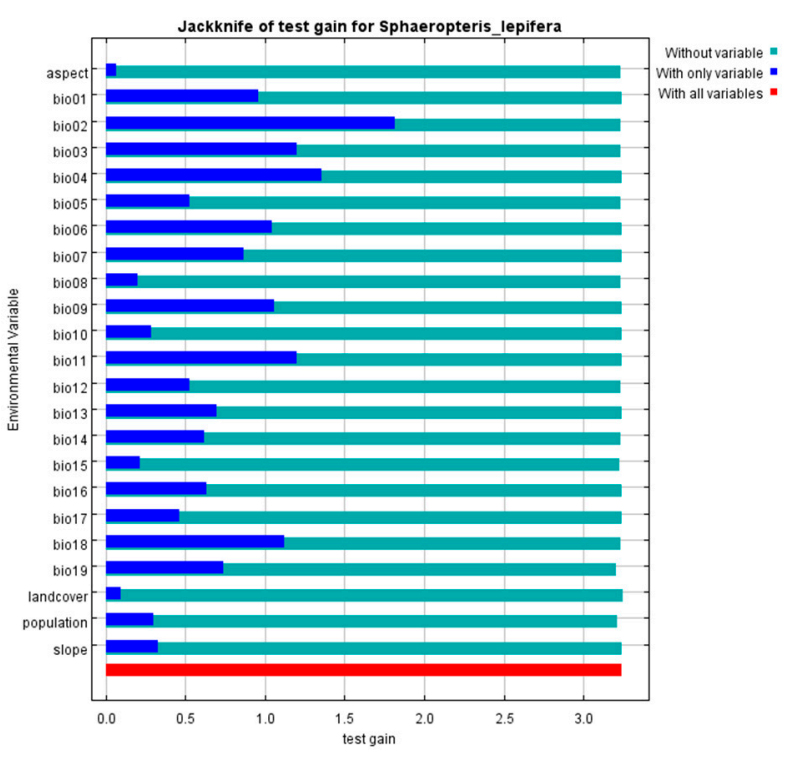

(C)

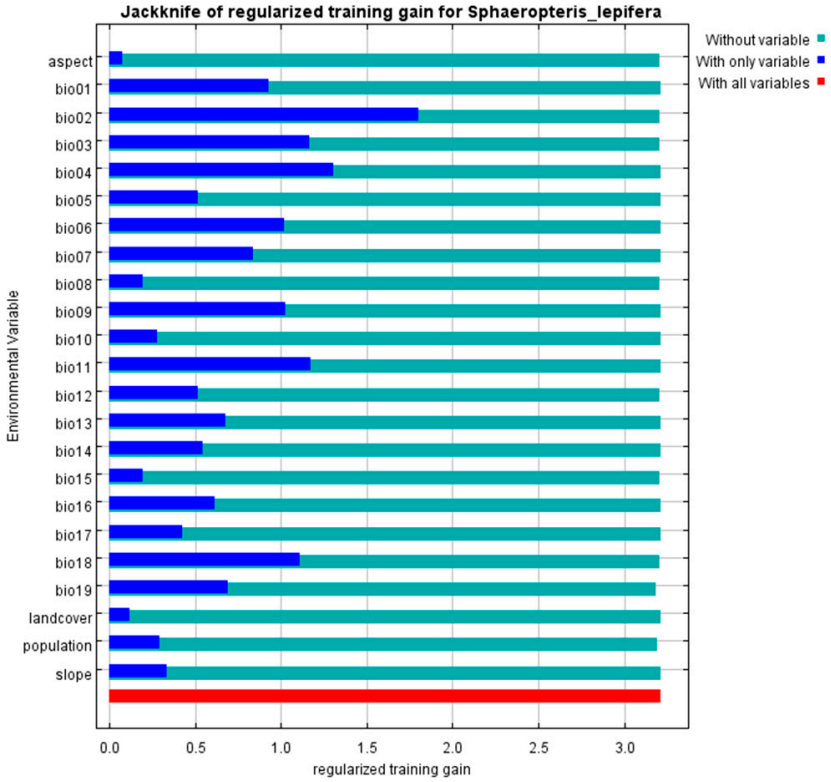

(B)

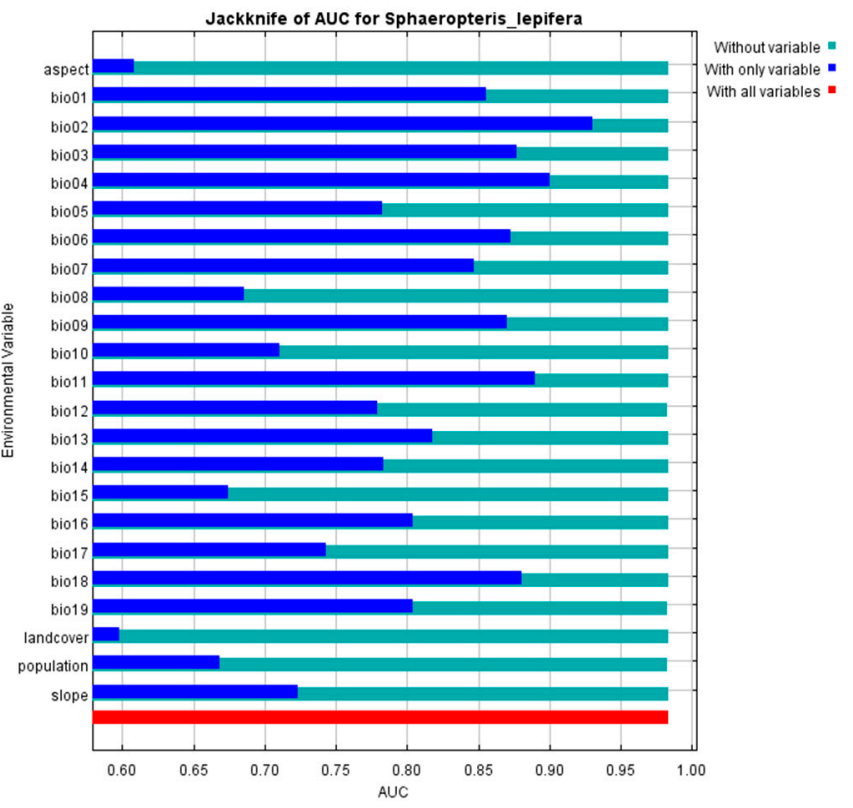

(D)

Figure 2. (A) ROC curve for MaxEnt prediction; (B) Result of the jackknife test of variable importance using training gain; (C) Result of the Jackknife test using test gain; (D) Result of the jackknife test using AUC on test data.

Although the sample size is small and the environmental variability limited due to geographic distance among reintroduction sites, it may be noteworthy that the site with the highest survival rate (after averaging among the three adjacent Shantao sites), Shaoguan (50\%), represents the extremes of all values shown to be important based on the various modes of testing within the ENM framework (Figure 3). Moreover, in several cases, the site with the second-highest survival rate, Shantao ( $38 \%$ average rate), is usually closer to the same extremes as Shaoguan compared to the other key variables. This is the case with annual precipitation, isothermality, and precipitation of the warmest quarter. This may further highlight the importance of these specific four variables for the survival of reintroduced plants. However, in some cases Shaoguan and Shantao are at opposite extremes of the environmental variables surveyed. This includes for mean diurnal range, temperature seasonality, mean temperature of the coldest quarter, and precipitation of the 
coldest quarter. These four variables are all related to temperature. Notably, at Shantao, meticulous management practices included mitigating the effects of temperature, especially during winter, possibly suggesting the feasibility of successful reintroduction even under less than ideal temperature conditions.

Table 3. All species recorded in quadrats established around adult individuals of Sphaeropteris lepifera on Nan'ao Island.

\begin{tabular}{|c|c|c|c|c|}
\hline Life Form & Frequency & Species & Drude Abundance & Relative Cover (\%) \\
\hline \multirow{8}{*}{ Tree } & \multirow{5}{*}{ Dominant species } & Machilus chinensis (Benth.) Hemsl. & Soc & 211 \\
\hline & & Schefflera heptaphylla (L.) Frodin & Soc & 136.5 \\
\hline & & Acacia confusa Merr. & Soc & 90 \\
\hline & & Cunninghamia lanceolata (Lamb.) Hook. & Soc & 89.1 \\
\hline & & Ilex viridis Champ. ex Benth. & Cop3 & 52.8 \\
\hline & \multirow[t]{2}{*}{ Companion species } & Litsea glutinosa (Lour.) C.B. Rob. & Cop2 & 36 \\
\hline & & Aporosa dioica (Roxb.) Müll. Arg. & $\mathrm{Sp}$ & 9 \\
\hline & Rare species & Archidendron lucidum (Benth.) I.C. Nielsen & Uni & 1.28 \\
\hline \multirow{3}{*}{ Shrub } & Dominant species & Psychotria rubra (Lour.) Poir. & $\mathrm{Sp}$ & 9.6 \\
\hline & \multirow{2}{*}{ Companion species } & Camellia sinensis (L.) Kuntze & Uni & 2.92 \\
\hline & & Diplospora dubia (Lindl.) Masam. & Uni & 1.44 \\
\hline \multirow{14}{*}{ Herb } & \multirow{2}{*}{ Dominant species } & Blechnum orientale $\mathrm{L}$. & Sol & 4.5 \\
\hline & & Boehmeria nivea (L.) Gaudich. & Sol & 3.5 \\
\hline & \multirow{5}{*}{ Companion species } & Eleutherococcus trifoliatus (L.) S.Y. Hu & Sol & 3 \\
\hline & & Cyclosorus parasiticus (L.) Farw. & Uni & 2.2 \\
\hline & & Alocasia odora (Roxb.) K. Koch & Uni & 2 \\
\hline & & Dryopteris fuscipes C. Chr. & Uni & 1.2 \\
\hline & & Pteris fauriei Hieron. & Uni & 0.6 \\
\hline & \multirow{7}{*}{ Rare species } & Deparia lancea (Thunb.) Fraser-Jenk. & Uni & 0.5 \\
\hline & & Adiantum flabellulatum $\mathrm{L}$. & Uni & 0.4 \\
\hline & & Lygodium japonicum (Thunb.) Sw. & Uni & 0.3 \\
\hline & & Mussaenda pubescens W.T. Aiton & Uni & 0.3 \\
\hline & & Alpinia hainanensis K. Schum. & Uni & 0.3 \\
\hline & & Solanum Americanum Mill. & Uni & 0.3 \\
\hline & & Liriope spicata (Thunb.) Lour. & Uni & 0.2 \\
\hline
\end{tabular}

Note: Soc, society; Cop, copiosa; Sp, sparsal; Sol, solitariae; Uni, unicum.

According the MaxEnt results, we divided predictions for S. lepifera into five categories: currently present, high habitat suitability, moderate suitability, low suitability, and unsuitable (Figure 4). Much of the area throughout Guangdong Province is moderately to highly suitable for large-scale reintroduction. This is in contrast to Guangxi Province, which has a very similar flora to Guangdong, sharing ca. 92\% of plant genera [48], and in both provinces, the flora has strongly tropical and subtropical characteristics. However, within Guangxi, mountainous terrain may affect critical environmental factors, such as temperature seasonality and precipitation of the coldest quarter, thus limiting the moderately suitable habitat for S. lepifera to areas along the border with Vietnam. Additionally, the MaxEnt model predicted that there are some places in Hong Kong that are highly suitable for introduction. 
Table 4. Comparison of environmental conditions between the reintroduced area and Nanao Island.

\begin{tabular}{|c|c|c|c|c|}
\hline & Nanao Island & $\begin{array}{l}\text { Maofeng } \\
\text { Mountain }\end{array}$ & Renhua County & Bajia Town \\
\hline City & Shantou & Guangzhou & Shaoguan & Yangchun \\
\hline Longitude & 117.07190393 & 113.444498 & 113.751431 & 111.520311 \\
\hline Latitude & 23.44393082 & 23.283165 & 25.07638 & 21.963179 \\
\hline Mean annual temperature & $21.5^{\circ} \mathrm{C}$ & $21.9^{\circ} \mathrm{C}$ & $19.6^{\circ} \mathrm{C}$ & $22.3^{\circ} \mathrm{C}$ \\
\hline Average annual precipitation & $1372.5 \mathrm{~mm}$ & $1623.6 \mathrm{~mm}$ & $1665 \mathrm{~mm}$ & $2392.3 \mathrm{~mm}$ \\
\hline Frost season & no & no & $57 \mathrm{~d}$ & no \\
\hline Annual minimum temperature & $8{ }^{\circ} \mathrm{C}$ & $3^{\circ} \mathrm{C}$ & $-3^{\circ} \mathrm{C}$ & $2{ }^{\circ} \mathrm{C}$ \\
\hline Coldest month & January & January & January & January \\
\hline $\begin{array}{l}\text { Mean temperature of the coldest } \\
\text { month }\end{array}$ & $14{ }^{\circ} \mathrm{C}$ & $15^{\circ} \mathrm{C}$ & $11^{\circ} \mathrm{C}$ & $16^{\circ} \mathrm{C}$ \\
\hline
\end{tabular}
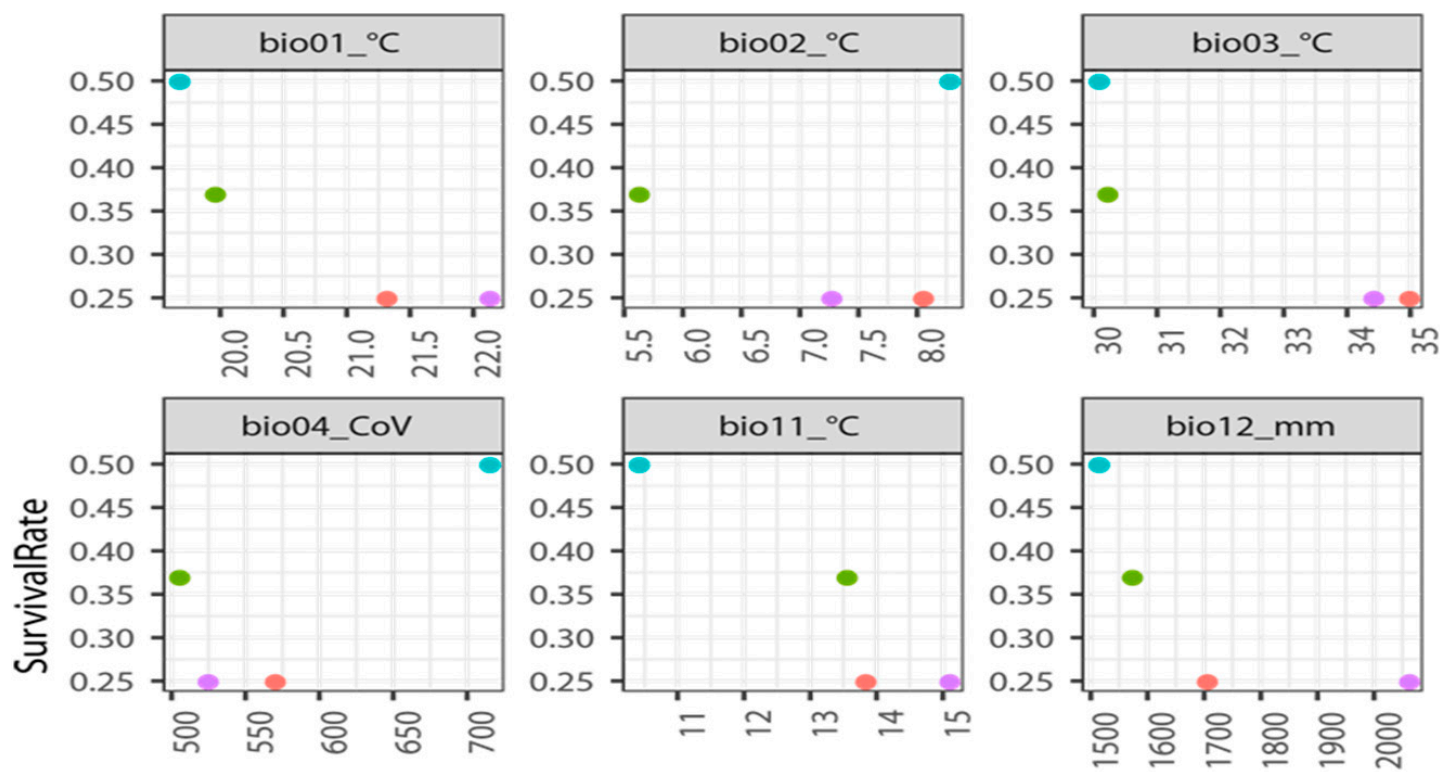

Cities

- Guangzhou

- Shantou-All

- Shaoguan

- Yangjiang
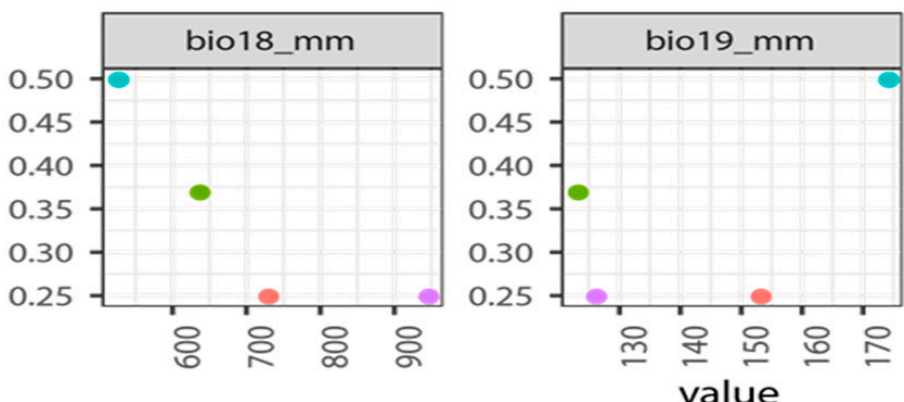

Figure 3. Survival rates of reintroduced seedlings at study sites based on the most important environmental variables according to assessments within the MaxEnt ENM framework. Survival rates were averaged across the three adjacent sites in Shantou, where the original population occurs. 


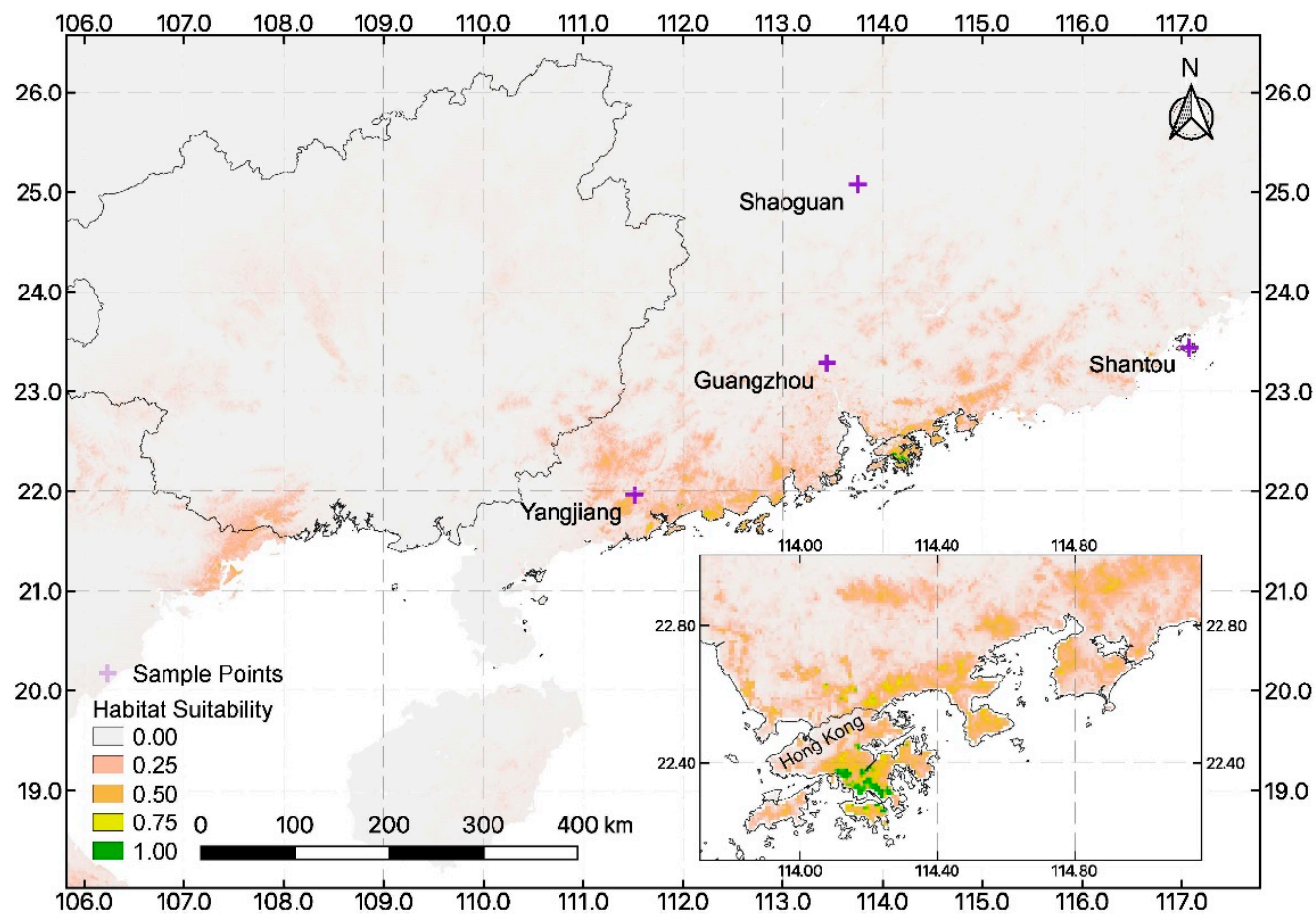

Figure 4. Prediction of habitat suitability for Sphaeropteris lepifera in eastern Asia.

\section{Discussion}

\subsection{Factors and Reasons Affecting the Distribution of Sphaeropteris lepifera during Life History}

We found that the rarity of $S$. lepifera may be due to the relatively large influence of environmental factors, especially temperature and available moisture, which appear critical to the transition between the gametophyte and sporophyte stages. S. lepifera generates spores twice yearly, at the end of April and the end of October. The process from spore dispersal to the formation of a sporophyte takes about three months so that the sporophytes should be formed in July-August and January-February. However, it happens that, within most of the native range of the species, January has the lowest temperature of the year (ca. about $14^{\circ} \mathrm{C}$ ) and represents the driest period. We observed in our germination experiments that lower temperatures and dry conditions led to lower rates of sporophytes production. Moisture is required for sperm to successfully fertilize archegonia, such that the moisture requirement is easily understood.

The role of temperature in the reproductive success of S. lepifera and its alteration of generations may be more complex. Although greenhouse-grown plants responded better to higher temperatures $\left(25^{\circ} \mathrm{C}\right)$ than lower ones $\left(18^{\circ} \mathrm{C}\right)$, we observed in the field that the Renhua area of Shaoguan, where the average monthly temperature is the lowest (Table 4), had more surviving plants than the other two places. This may be due to watering frequency by the management, as watering (and other maintenance) is well-known to improve plant growth of ferns introduced (or reintroduced) into the wild [49]. However, several species of the Cyatheaceae fern family, to which S. lepifera belongs, are known to be sensitive to phosphorus and have very specific requirements for this nutrient [50]. Phosphorus requires a higher energy investment to take up under higher temperatures [51], and while this may not be limiting for greenhouse-grown plants, it may have affected those reintroduced in wild areas. Thus, the interplay and balance between higher temperature preferences and investments in nutrient uptake at reintroduction should be examined in future studies.

4.2. Factors and Causes of Community Composition Affecting the Distribution of Sphaeropteris lepifera

Although we observed that Acacia confusa and Pinus massoniana were the dominant trees on Nan'ao Island, they were not the dominant species within the plot cen- 
tered around mature individuals of $S$. leipifera. In fact, the $20 \times 20 \mathrm{~m}$ plot contained no Pinus massoniana and only one Acacia confusa. Normally, Acacia confusa is $15 \mathrm{~m}$ in height while Pinus massoniana can reach $45 \mathrm{~m}$. This is in contrast to S. lepifera, which reaches only ca. $8 \mathrm{~m}$. The demand for light by mature $S$. lepifera would make it hard for these species to compete with tall trees. Overall, the average height of the community around the S. lepifera individuals was ca. $10 \mathrm{~m}$, with the tallest species being Machilus chinensis and Cunninghamia lanceolata. These species are not normally so short in stature nor is the Acacia confusa also found in the plot. Their small stature may relate to the occurrence of the community on a south-facing slope. Notably, shrub species within the community, such as Archidendron lucidum, were taller than normal. This suggests that slope and aspect may also be critical factors affecting suitable habitat for $S$. lepifera, which may be better able to compete within environments that tend towards supporting lower canopy heights, either through recruitment of mainly short-stature trees or by limiting the growth of typically taller ones. This is also consistent with prior studies, which have shown that tree ferns commonly colonize light gaps within a canopy resulting from disturbances such as high wind, landslides, or other natural or anthropogenic causes [52,53].

\subsection{Suitable Habitat for Reintroduction within the Chinese Mainland and Near-Shore Islands}

In recent years, due to the rarity of wild S. lepifera on the China mainland, some plants were introduced at botanical gardens for protection. For example, South China Botanical Garden, Chinese Academy of Sciences and Xiamen Botanical Garden have successfully cultivated wild-sourced $S$. lepifera and possess thriving adults that are generating new fiddleheads and spores. Despite these successes with ex-situ conservation, in-situ conservation offers the advantages of facilitating long-term population health through natural selection and of supporting natural ecosystem services [54].

We base our recommendations for reintroduction of $S$. lepifera on our results and the prior work of Wei et al. [55] regarding the successful reintroduction of the endangered orchid, Bletilla striata (Thunb.) Rchb.f. This orchid has similar habitat requiremnets to S. lepifera, so we believe that protocols leading to its successful reintroduction may also be applicable to S. lepifera. Ideally, areas for reintroduction of S. lepifera in the wild should meet the following basic conditions: (1) be far away from villages and highways and relatively inaccessible to people to reduce anthropogenic disturbance; (2) have trees with average heights not be more than $10 \mathrm{~m}$ with small trees and shrubs as the dominant species and (3) be a moist environment, such as with a nearby water source, ideally at the foot of a shady slope. During reintroduction, we recommend the following steps to promote greater success: (1) plant in a scattered pattern and not too densely; (2) water frequently during dry periods from January to February or July to August or during drought, especially when drought occurs in the first six months after planting; and (3) perform preliminary in-situ experiments prior to large-scale transplanting, focusing on whether there are animal, disease, or other factors potentially affecting the survival of transplanted individuals in the local area.

Both ex-situ and in-situ conservation have advantages and disadvantages. For in-situ conservation, the disadvantages are that it requires a greater investment of time and money and, as evidenced from the recommendations above, the procedures are often cumbersome. However, given the aforementioned advantages, a model that utilizes both in situ and ex situ strategies for $S$. lepifera may be beneficial for the species. Considering the ornamental, economic, and medicinal value of S. lepifera [10,13-15], it could be widely promoted for cultivation in Guangdong Province, such as in parks or within urban landscaping, especially with orchids, for which its trunk is an important substrate for epiphytic growth.

The reason why many endangered plants cannot be cultivated at a large scales is that their unique, strict environmental requirements and the growing conditions lead to high maintenance costs. However, our work may not only provide a framework to support in-situ conservation of $S$. lepifera, but also finding suitable habitats for it and maintaining 
it within urban green spaces. Thus, our findings may help to reduce the costs of ex-situ conservation efforts.

Supplementary Materials: The following are available online at https:/ / www.mdpi.com/article/10 $.3390 /$ horticulturae7110496/s1, Table S1. Distribution information of Sphaeropteris lepifera.

Author Contributions: Conceptualization, X.W., A.H. and F.W.; methodology, Y.C. and A.H.; software, Y.C.; validation, A.H., F.W., Y.C. and X.W.; formal analysis, X.W. and A.H.; investigation, F.W., Y.D., H.H., X.Y. and R.J.; resources, F.W. and X.W.; data curation, X.W., A.H. and F.W.; writingoriginal draft preparation, X.W., A.H. and Y.C.; writing-review and editing, X.W., A.H. and F.W.; visualization, X.W.; supervision, F.W.; project administration, F.W.; funding acquisition, F.W. All authors have read and agreed to the published version of the manuscript.

Funding: This research was funded by grants from the Strategic Priority Research Program of the Chinese Academy of Sciences (grant number XDA13020601), Agricultural Biodiversity Investigation and Protection Technology System Construction Project (grant number 0835-210Z32104471), Guangdong Province Enterprise Science and Technology Special Commissioner Project (grant number GDKTP2020047500) and Guangdong Wildlife Protection and Management Project (grant number Y936061001).

Institutional Review Board Statement: Not applicable.

Informed Consent Statement: Not applicable.

Data Availability Statement: The data presented in this study are available on request from the corresponding author (F.-G.W.). It can be downloaded from the supporting files.

Acknowledgments: The authors would like to thank Jinfang Cai, Shaohui Wang and Jiyun Li of Shantou Nan'ao County Bureau of natural resources for their assistance with the field work, and Zhiqiang Song of South China Botanical Garden, Chinese Academy of Sciences for his assistance with the experiments observation.

Conflicts of Interest: The authors declare no conflict of interest.

\section{References}

1. Ehlers, E.; Krafft, T. The "Anthropocene". In Earth System Science in the Anthropocene; Springer: Berlin/Heidelberg, Germany, 2006; pp. 13-18.

2. Harris, A.; Stefanie, I.B.; Aarón, R. Long distance dispersal in the assembly of floras: A review of progress and prospects in north America. J. Syst. Evol. 2018, 56, 430-448. [CrossRef]

3. Xu, W.B.; Svenning, J.C.; Chen, G.K.; Zhang, M.G.; Huang, J.H.; Chen, B.; Ordonez, A.; Ma, K.P. Human Activities Have Opposing Effects on Distributions of Narrow-Ranged and Widespread Plant Species in China. Proc. Natl. Acad. Sci. USA 2019, 116, 266-274. [CrossRef]

4. Peterson, A.T. Uses and requirements of ecological niche models and related distributional models. Biodivers. Inform. 2006, 3, 59-72. [CrossRef]

5. Blonder, B. Hypervolume concepts in niche- and trait-based ecology. Ecography 2018, 41, 1441-1455. [CrossRef]

6. Peterson, A.T.; Pape, M.; Soberón, J. Mechanistic and correlative models of ecological niches. Eur. J. Ecol. 2015, 1, 28-38. [CrossRef]

7. Phillips, S.J.; Anderson, R.P.; Schapire, R.E. Maximum Entropy Modeling of Species Geographic Distributions. Ecol. Model. 2006, 190, 231-259. [CrossRef]

8. Carsten, F.D.; Stanislaus, J.S.; Juliano, C.; Isabelle, C.; Catherine, G.; Florian, H.; Michael, K.; Xavier, M.; Römermann, C.; Schröder, B.; et al. Correlation and process in species distribution models: Bridging a dichotomy. J. Biogeogr. 2012, 39, $2119-2131$.

9. GBIF.org. GBIF Occurrence Download. Available online: https://doi.org/10.15468/dl.j8abq5 (accessed on 5 July 2021). [CrossRef]

10. Zhang, X.C.; Zhang, L.B. Cyatheaceae. In Flora of China; Wu, Z.Y., Raven, P.H., Hong, D.Y., Eds.; Science Press: Beijing, China, 2013; Volume 2, pp. 134-138.

11. Gu, Y.F.; Jiang, R.H.; Liu, B.D.; Yan, Y.H. Sphaeropteris guangxiensis Y. F. Gu \& Y. H. Yan (Cyatheaceae), a new species of tree fern from Southern China. Phytotaxa 2021, 518, 69-74.

12. National Forestry and Grassland Administration, Ministry of Agriculture and Rural Affairs. List of National Key Protected Wild Plants in China. 2021-9-7. Available online: http://www.gov.cn/zhengce/zhengceku/2021-09/09/content_5636409.htm (accessed on 25 September 2021).

13. Ye, H.G. Chinese Medicinal Plants; Chemical Industry Press: Beijing, China, 2017; Volume 25, pp. 356-357.

14. Shi, L. Ornamental Ferns of China; China Forestry Publishing House: Beijing, China, 2002; p. 87.

15. Fujian Forestry Department. Sphaeropteris lepifera (J. Sm. ex Hook.). For. China 2003, 11, 29. 
16. Morigengaowa, H.S.; Liu, B.; Kang, M.; Yan, Y. One or More Species? GBS Sequencing and Mmorphological Traits Evidence Reveal Species Diversification of Sphaeropteris brunoniana in China. Biodivers. Sci. 2019, 27, 36-44. [CrossRef]

17. Huang, C.H.; Qi, X.P.; Chen, D.Y.; Qi, J.; Ma, H. Recurrent genome duplication events likely contributed to both the ancient and recent rise of ferns. J. Integr. Plant Biol. 2020, 62, 433-455. [CrossRef]

18. Chen, X.X.; Pan, T.Z. The Report of a New Record Genera (Sphaeropteris) and a New Record Species (Cyathea lepifera) from Zhejiang, China. J. Wenzhou Univ. 2016, 37, 34-37.

19. Yin, H. Rare and Endangered Plants in China; China Forestry Publishing House: Beijing, China, 2013; pp. 13-26.

20. Zhao, X.Q. The Rare Wild Tree Fern Found in Xiamen: Sphaeropteris lepifera (J. Sm. ex Hook.) (Cycinaceae). Wuyi Sci. J. 1983, 3 , 181.

21. Ebihara, A.; Yamaoka, A.; Mizukami, N.; Sakoda, A.; Nitta, J.H.; Imaichi, R. A survey of the fern gametophyte flora of japan: Frequent independent occurrences of noncordiform gametophytes. Am. J. Bot. 2013, 100, 735-743. [CrossRef] [PubMed]

22. Pelser, P.B.; Barcelona, J.F.; Nickrent, D.L. (Eds.) 2011 Onwards. Co's Digital Flora of the Philippines. Available online: www.philippineplants.org (accessed on 20 September 2021).

23. Barcelona, J.F. The Taxonomy and Ecology of the Pteridophytes of Mt. Iraya and Vicinity, Batan Island, Batanes Province, Northern Philippines. In Pteridology in the New Millennium; Springer: Dordrecht, The Netherlands, 2003. [CrossRef]

24. Holttum, R.E. Tree-Ferns of the Genus Cyathea Sm. in Asia (Excluding Malaysia). Kew Bull. 1965, 19, 463-487. [CrossRef]

25. Wang, B.S.; Yu, S.X.; Peng, S.L.; Li, M.G. Handbook of Plant Community Experiments; Guangdong Higher Education Press: Guangzhou, China, 1996.

26. Ji, S.B.; Xiang, J.Y.; Liu, B.D.; Ji, H.L. Behavior and Morphology of Sphaeropteris lepifera (J. Sm. ex Hook.) (Cyatheaceae) Swimming Sperm. Acta Bot. Boreali-Occident. Sin. 2018, 38, 92-97.

27. Zhang, X.; Xiang, J.J.; Xiao, X.; Ji, S.B.; Liu, B.D. Influence of Lead and Cadmium Stress on Sperm's Behavior and Morphology of Sphaeropteris lepifera (J. Sm. ex Hook.) (Cyatheaceae). Acta Bot. Boreali-Occident. Sin. 2019, 5, 776-783.

28. Cheng, M.C.; You, C.F. Sources of major ions and heavy metals in rainwater associated with typhoon events in southwestern taiwan. J. Geochem. Explor. 2010, 105, 106-116. [CrossRef]

29. Jiao, Y.; Wang, H.; Zhang, S.Z. Fern Atlas; China Forestry Publishing House: Beijing, China, 2014.

30. Wang, J.J.; Zhang, X.C.; Liu, B.D.; Cheng, X. Gametophyte Development of Three Species in Cyatheaceae. J. Trop. Subtrop. Bot. 2007, 15, 115-120.

31. Wani, I.A.; Verma, S.; Mustahq, S.; Alsahli, A.A.; Alyemeni, M.N.; Tariq, M.; Pant, S. Ecological analysis and environmental niche modelling of D. hatagirea (D. Don) Soo: A conservation approach for critically endangered medicinal orchid. Saudi J. Biol. Sci. 2021, 28, 2109-2122. [CrossRef]

32. Papeş, M.; Gaubert, P. Modelling ecological niches from low numbers of occurrences: Assessment of the conservation status of poorly known viverrids (Mammalia, Carnivora) across two continents. Divers. Distrib. 2010, 13, 890-902. [CrossRef]

33. Banks, S.C.; Finlayson, G.R.; Lawson, S.J.; Lindenmayer, D.B.; Paetkau, D.; Ward, S.J.; Taylor, A.C. The effects of habitat fragmentation due to forestry plantation establishment on the demography and genetic variation of a marsupial carnivore, Antechinus agilis. Biol. Conserv. 2005, 122, 581-597. [CrossRef]

34. Rhodes, J.R.; Wiegand, T.; McAlpine, C.A.; Callaghan, J.; Lunney, D.; Bowen, M.; Possingham, H.P. Modeling species' distributions to improve conservation in semiurban landscapes: Koala case study. Conserv. Biol. 2006, 20, 449-459. [CrossRef] [PubMed]

35. Li, X.; Fu, L.; Wang, F.G.; Xing, F.W. Michelia guang $\neg$ dongensis (Magnoliaceae), an Endangered Plant Species with Ex-tremely Small Population, should be Evaluated as CR C2a (i); D. Biodivers. Sci. 2017, 25, 91-93. [CrossRef]

36. Ren, Z.; Chen, L.; Peng, H. Orophea yunnanensis should be Listed as a Plant Species with Extremely Small Population. Biodivers. Sci. 2016, 24, 358-359. (In Chinese) [CrossRef]

37. Ptsch, R.; Jaková, A.; Chytr, M.; Kucherov, I.B.; Janssen, J. Making them visible and usable-vegetation lot observations from fennoscandia based on historical species quantity scales. Appl. Veg. Sci. 2019, 22, 465-473. [CrossRef]

38. Ma, H.N.; Li, Y.; Tan, L.Y.; Liu, B.D. Spore Propagation and Rejuvenation of Sphaeropteris lepifera (J. Sm. ex Hook.). Acta Hortic. Sin. 2010, 37, 1679-1684.

39. Robert, J.H.; Phillips, S.; Leathwick, J.; Elith, J. Dismo: Species Distribution Modeling. R Package Version 1.3-3. Available online: https:/ /CRAN.R-project.org/package=dismo (accessed on 10 September 2020).

40. R Core Team. R: A Language and Environment for Statistical Computing; R Foundation for Statistical Computing: Vienna, Austria. Available online: https:/ / www.R-project.org/ (accessed on 12 June 2021).

41. Tennekes, M. tmap: Thematic Maps in R. J. Stat. Softw. 2018, 84, 1-39. [CrossRef]

42. Fick, S.E.; Hijmans, R.J. Worldclim 2: New 1-km spatial resolution climate surfaces for global land areas. Int. J. Climatol. 2017, 37, 4302-4315. [CrossRef]

43. Booth, T.H.; Nix, H.A.; Busby, J.R.; Hutchinson, M.F. Bioclim: The first species distribution modelling package, its early applications and relevance to most current MaxEnt studies. Divers. Distrib. 2014, 20, 1-9.

44. Zuo, H.; Hutchinson, M.F.; Mcmahon, J.P.; Nix, H.A. Developing a mean monthly climatic database for China and Southeast Asia. In Proceedings of the International Workshop Held in Bangkok: Matching Trees and Sites, Bangkok, Thailand, 27-30 March 1995. 
45. Buchhorn, M.; Smets, B.; Bertels, L.; Lesiv, M.; Tsendbazar, N.-E.; Masiliunas, D.; Linlin, L.; Herold, M.; Fritz, S. Copernicus Global Land Service: Land Cover 100 m: Collection 3: Epoch 2019: Globe (Version V3.0.1) [Data set]. Zenodo. 2020. Available online: https:/ /land.copernicus.eu/global/products/lc (accessed on 10 July 2021).

46. WorldPop (www.worldpop.org-School of Geography and Environmental Science, University of Southampton; Department of Geography and Geosciences, University of Louisville; Departement de Geographie, Universite de Namur) and Center for International Earth Science Information Network (CIESIN), Columbia University. Global High Resolution Population Denominators Project-Funded by the Bill and Melinda Gates Foundation (OPP1134076). 2018. Available online: https://www. worldpop.org / geodata/summary?id=94 (accessed on 10 September 2020).

47. Chitta, R.D.; Jamir, N.S.; Zubenthung, P.K. Distribution Prediction Model of a Rare Orchid Species (Vanda bicolor Griff.) Using Small Sample Size. Am. J. Plant Sci. 2017, 8, 1388-1398.

48. Su, Z.R.; Zhang, H.D. The Relationship between the Flora of Guangxi and the Flora of Neighboring Areas. J. South China Agric. Univ. 1994, 15, 38-43.

49. Riano, K.; Briones, O. Sensitivity of three tree ferns during their first phase of life to the variation of solar radiation and water availability in a mexican cloud forest. Am. J. Bot. 2015, 102, 1472-1481. [CrossRef] [PubMed]

50. Brock, J.M.R.; Burns, B.R.; Perry, G.; Lee, W.G. Gametophyte niche differences among sympatric tree ferns. Biol. Lett. 2019, 15, 20180659. [CrossRef] [PubMed]

51. Fisher, J.B. Carbon cost of plant nitrogen acquisition: A mechanistic, globally applicable model of plant nitrogen uptake, retranslocation, and fixation. Glob. Biogeochem. Cycles 2010, 24. [CrossRef]

52. Brock, J.; Perry, G.; Lee, W.G.; Burns, B.R. Tree fern ecology in New Zealand: A model for southern temperate rainforests. For. Ecol. Manag. 2016, 375, 112-126. [CrossRef]

53. Bernabe, N.; Williams-Linera, G.; Palacios-Rios, M. Tree ferns in the interior and at the edge of a mexican cloud forest remnant: Spore germination and sporophyte survival and establishment1. Biotropica 1999, 31, 83-88.

54. Rotach, P. In situ conservation methods. In Conservation and Management of Forest Genetic Resources in Europe; Geburek, T., Turok, J., Eds.; Arbora Publishers: Zvolen, Slovakia, 2005; pp. 535-565.

55. Wei, K.H.; Liang, Y.; Yang, C.; Li, L.X.; Hu, Y.; Liao, J.H.; Gao, W.Y. Conservation Research of Bletilla striata. Mod. Chin. Med. 2019, 21, 689-693. 